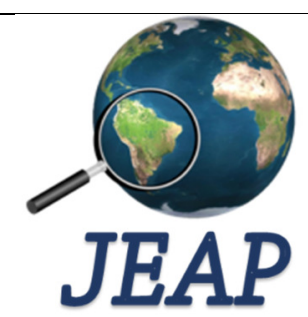

ISSN: 2525-815X

\section{Journal of Environmental} Analysis and Progress

Journal homepage: www.jeap.ufrpe.br/

10.24221/jeap.2.4.2017.1471.499-508

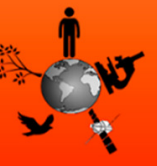

\title{
Tratamentos pré-germinativos em sementes de espécies da Caatinga
}

\section{Pre-germinating treatments in seeds of Caatinga species}

Jéssica Vanessa Góis de Siqueira ${ }^{a}$, João Paulo Alves de Barros ${ }^{\mathrm{a}}$, Yara Panta de Araújo ${ }^{\mathrm{a}}$, Thieres George Freire da Silva ${ }^{a}$, Luciana Sandra Bastos de Souza ${ }^{a}$

a Universidade Federal Rural de Pernambuco-UFRPE, Unidade Acadêmica de Serra Talhada-UAST, Rua Gregório Ferraz Nogueira, S/N, José Tomé de Souza Ramos, Serra Talhada-PE, Brasil. CEP: 59300-000. E-mail: jessicasiiqueira@hotmail.com; paulo_lotd@hotmail.com; y.araujo22@gmail.com; thigeoprofissional@hotmail.com; sanddrabastos@yahoo.com.br.

\section{A R T I C L E I N F O}

Recebido 02 Jul 2017

Aceito 27 Jul 2017

Publicado 13 Out 2017

\begin{abstract}
A B S T R A C T
Some species of the Caatinga present seeds with dormancy, a mechanism that allows germination when the environmental conditions permit its establishment and survival; this feature is advantageous for the perpetuation and undesirable for producers that need a fast production of these plants. The study aimed to evaluate the efficiency of the application of pre-germination treatments in Angico (Anadenanthera colubrina) (Vell.) Brenan, Jurema-branca (Piptadenia stipulacea Benth.) Ducke and Mulungu (Erythrina velutina Willd.). Two independent experiments were carried out at the Serra Talhada Academic Unit using Angico, Jurema-branca and Mulungu seeds, arranged in a completely randomized design, with four replicates and 15 seeds. The seeds were submitted to pre-germination treatments: T1-control, T2-mechanical scarification on the opposite end of the thread with wood sandpaper, T3-mechanical scarification on the opposite end of the thread with wood sandpaper + immersion in water at room temperature for 24 hours and T4-heat treatment with Immersion in water at $80^{\circ} \mathrm{C}$ for 2 minutes. The parameters evaluated the efficiency: germination percentage and rate of emergence (IVE), biometric data (30 days after sowing), as seedling height, the number of leaves and stem diameter. The seeds of Jurema-branca ( $P$. stipulacea) and Mulungu (E. velutina), submitted to the pre-germinative treatments $\mathrm{T} 2$ and $\mathrm{T} 3$, showed better germinative performance, reflected in the growth of the seedling. The Angico (A. colubrina) was not sensitive to the application of the treatments, and its germination was nullified for the T3 treatment application. In all cases, variations of the parameters were observed because of the atmospheric conditions.
\end{abstract}

Keywords: Semi-arid, dormancy, emergency, Angico, Jurema-branca, Mulungu.

\section{R E S U M O}

Algumas espécies da Caatinga apresentam sementes com dormência, um mecanismo que permite a germinação quando as condições ambientais propiciarem seu estabelecimento e sobrevivência; esta característica é vantajosa para a perpetuação e indesejável para os produtores que necessitam de uma rápida produção destas plantas. O estudo objetivou avaliar a eficiência da aplicação de tratamentos pré-germinativos em sementes de Angico (Anadenanthera colubrina) (Vell.) Brenan, Jurema-branca (Piptadenia stipulacea) (Benth.) Ducke e Mulungu (Erythrina velutina Willd.). Foram conduzidos dois experimentos independentes na Unidade Acadêmica de Serra Talhada. Sementes de Angico, Jurema-branca e Mulungu foram dispostas em delineamento experimental inteiramente casualizado, com quatro repetições e 15 sementes. Foram aplicados os tratamentos pré- 
germinativos: T1-testemunha, T2-escarificação mecânica em extremidade oposta ao hilo com lixa de madeira, T3-escarificação mecânica em extremidade oposta ao hilo com lixa de madeira + imersão em água sob temperatura ambiente por 24 horas e T4-tratamento térmico com imersão em água a $80^{\circ} \mathrm{C}$ por 2 minutos. A eficiência foi avaliada pelos parâmetros: porcentagem de germinação e índice de velocidade de emergência (IVE), dados biométricos (30 dias após a semeadura), como altura das plântulas, número de folhas e diâmetro do coleto. As sementes de Juremabranca ( $P$. stipulacea) e Mulungu (E. velutina), submetidas aos tratamentos prégerminativos T2 e T3, apresentaram melhores desempenhos germinativos, refletidos no crescimento da plântula. O Angico (A. colubrina) não se mostrou sensível à aplicação dos tratamentos e a germinação foi anulada em decorrência da aplicação do tratamento T3. Em todos os casos foram observadas variações nos parâmetros em decorrência, possivelmente, das condições atmosféricas.

Palavras-Chave: Semiárido, dormência, emergência, Angico, Jurema-branca, Mulungu.

\begin{abstract}
Introdução
O Semiárido brasileiro possui uma área de, aproximadamente, $980.133,079 \quad \mathrm{~km}^{2}$, representando cerca de $11 \%$ do território nacional (ISNA, 2017), caracterizada pela irregularidade das chuvas e baixos índices pluviométricos, além da elevada demanda atmosférica (Marengo et al., 2011). Para suportar estas condições, a vegetação nela estabelecida, a caatinga, apresenta mecanismos de resistência ao déficit hídrico (Barreto \& Barbosa, 2001). Dentre estas, o angico (Anadenanthera colubrina (Vell.) Brenan), a jurema-branca (Piptadenia stipulacea (Benth.) Ducke) e o mulungu (Erythrina velutina Willd.) se destacam pelo crescimento rápido, sendo utilizadas com finalidades econômicas e ecológicas (Lorenzi, 2008; Bezerra, 2008; Lorenzi, 2009), mas podem ter seu
\end{abstract} estabelecimento limitado pelo déficit de água.

A germinação das sementes e a produção de mudas podem ser alteradas em decorrência do seu vigor, temperatura, salinidade do solo (Andréo-Souza, 2010), do substrato, da sensibilidade à luminosidade (Alves, 2011) e, principalmente, ao déficit hídrico (Pereira, 2013). No caso de algumas espécies da Caatinga, as sementes apresentam dormência, um mecanismo que permite a germinação apenas quando a condição ambiental propicia seu estabelecimento e sobrevivência; esta característica se torna vantajosa para a perpetuação da espécie e é indesejável para os produtores que necessitam de uma rápida germinação (Azeredo et al., 2010).

Para que haja superação da dormência, vários processos podem ser adotados, dentre os quais podem ser citados: escarificação química (Pacheco et al., 2007; Azeredo et al., 2010; Pelazza, Segato \& Romanato, 2011); escarificação mecânica com material abrasivo (Guedes et al., 2013), seccionamento ou remoção do tegumento (Pacheco et al., 2007); tratamentos térmicos (Pelazza, Segato \& Romanato, 2011; Farias et al., 2013) e estratificação (Peche et al., 2016). Estes métodos foram utilizados por vários autores para espécies nativas, e podem apresentar resultados distintos em função da época do ano, da espécie analisada, dentre outros. O objetivo deste estudo foi avaliar o uso de tratamentos pré-germinativos simples para a superação da dormência em sementes de espécies estabelecidas no semiárido.

\section{Material e Métodos}

Neste estudo foi avaliada a superação da dormência em sementes das espécies: Angico ( $A$. colubrina), Jurema-branca $(P$. stipulacea $)$ e Mulungu (E. velutina), em diferentes épocas do ano.

Foram conduzidos dois experimentos independentes, sendo o primeiro durante o período de 17 de maio à 07 de julho de 2016 e o segundo de 06 de abril à 10 de maio de 2017. Em ambos os casos, os estudos foram realizados na Unidade Acadêmica de Serra Talhada-UAST (Latitude: $07^{\circ}$ 95'42' ' S; Longitude: $38^{\circ} 29^{\prime} 50^{\prime \prime}$ O e Altitude: $499 \mathrm{~m}$ ) (Figura 1), pertencente à Universidade Federal Rural de PernambucoUFRPE, no município de Serra Talhada-PE.

O clima da região, segundo a classificação de Köppen, é do tipo BSwh', semiárido, onde são encontradas, normalmente, altas taxas de evapotranspiração em função da combinação de temperaturas médias altas em torno de $26^{\circ} \mathrm{C}$, umidade relativa média anual baixa próximo a $63 \%$ e precipitação pluviométrica acumulada baixa da ordem $642 \mathrm{~mm}$. ano $^{-1}$ (Alvares et al., 2013; Pereira et al., 2015). A temperatura e a umidade atmosférica, durante as duas épocas distintas, foram monitoradas através de uma estação meteorológica automática, localizada a cerca de $300 \mathrm{~m}$ da área experimental e pertencente ao Instituto Nacional de Meteorologia-INMET (INMET, 2017). Na Figura 2 constata-se que, embora os experimentos tenham sido conduzidos em épocas do ano semelhantes, na primeira época, as condições atmosféricas locais, representadas 
pela temperatura e umidade relativa do ar, foram mais rigorosas em relação à segunda.
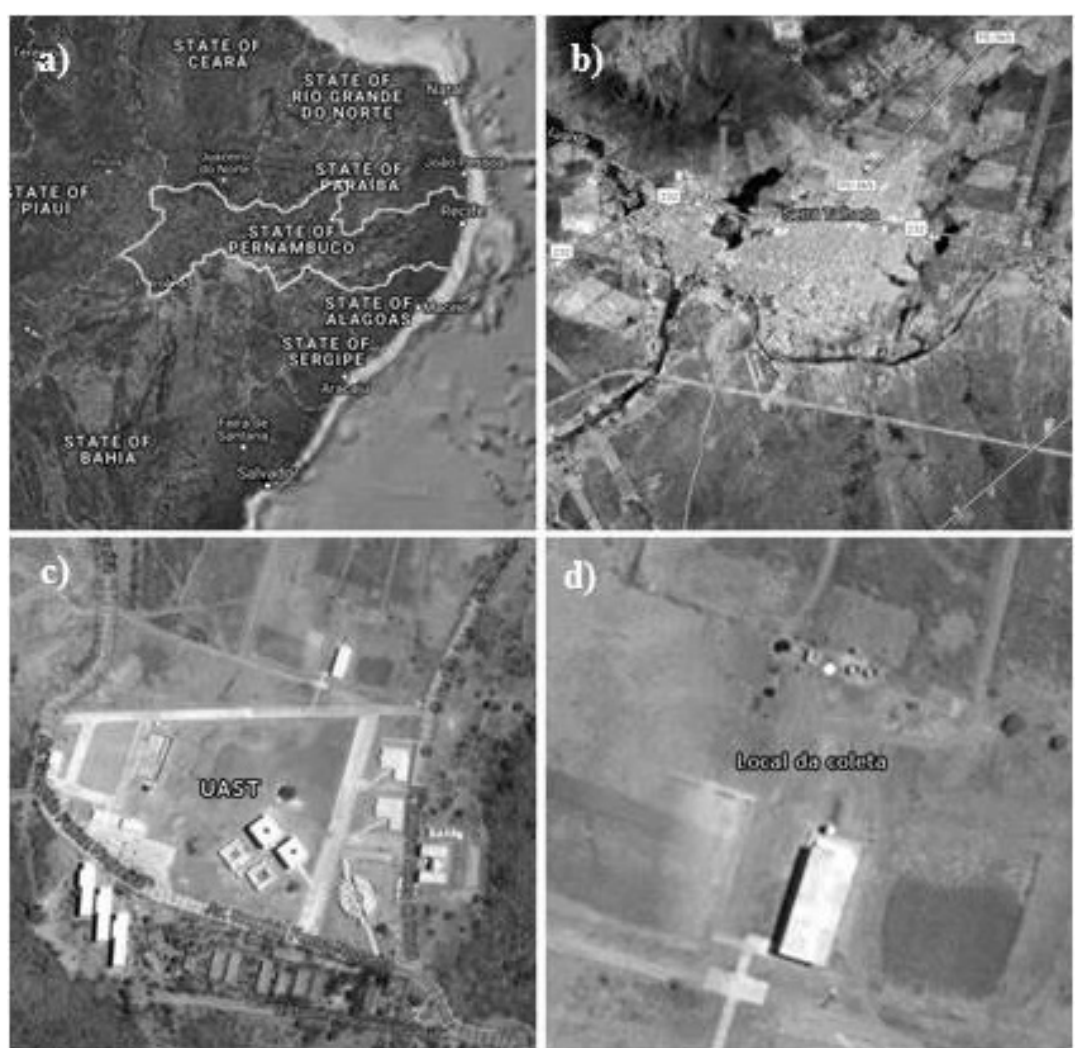

Figura 1. Localização da área de estudo. (a) Estado de Pernambuco, (b) Município de Serra Talhada, (c) Universidade Federal Rural de Pernambuco, Unidade Acadêmica de Serra Talhada, (d) Local de coleta das amostras de solo. Fonte: Google Earth ${ }^{\mathrm{TM}}$ (2017).

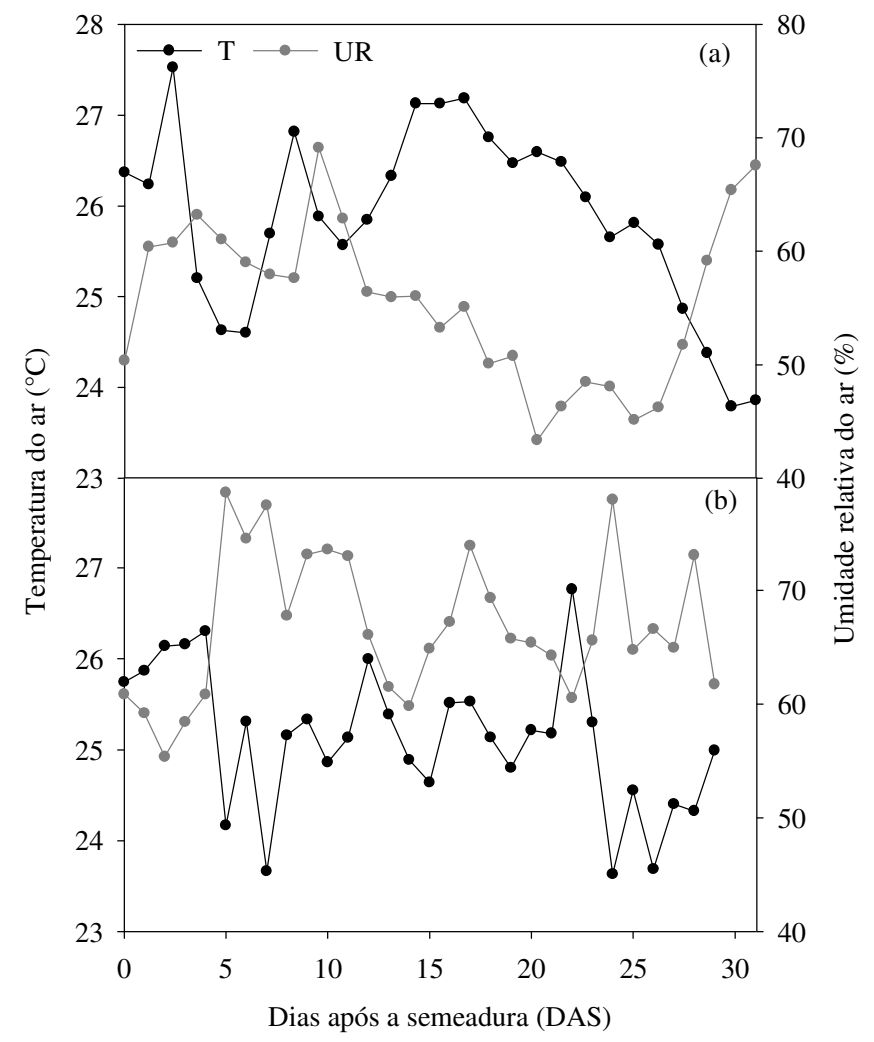

Figura 2. Comportamento da temperatura e umidade relativa do ar durante a primeira (a) e segunda época (b) de observação em Serra Talhada, PE. 
Inicialmente foi realizada a coleta de amostras de solo na área experimental para a determinação das características físicas. As amostras foram obtidas, aleatoriamente, com auxílio de trado e uma marreta, nas profundidades de 0-20 e 20-40 cm (Tabela 1). O solo foi classificado como Cambissolo Háplico Ta Eutrófico típico (EMBRAPA, 2013).

Tabela 1. Caracterização física de um Cambissolo Háplico Ta Eutrófico típico em diferentes profundidades, no município de Serra Talhada-PE, 2017.

\begin{tabular}{ccccccc}
\hline Profundidades & $\boldsymbol{\rho}_{\mathbf{s}}$ & $\boldsymbol{\rho}_{\mathbf{p}}$ & $\boldsymbol{\varphi t}$ & Areia total & Silte & Argila \\
\hline $\mathbf{C m}$ & \multicolumn{1}{c}{$\mathbf{k g ~ d m}$} & $\mathbf{\%}^{-3}$ & & & $\mathbf{g ~ k g}^{-1}$ & \\
\hline $0-20$ & 1,30 & 2,5 & 48,3 & 815,2 & 128,4 & 56,4 \\
$20-40$ & 1,32 & 2,5 & 47,9 & 828,5 & 134,3 & 37,1 \\
\hline
\end{tabular}

$\rho_{\mathrm{s}}=$ Densidade do solo; $\rho_{\mathrm{p}}=$ Densidade das partículas; $\varphi \mathrm{t}=$ Porosidade total do solo.

Utilizaram-se as espécies: Angico (A. colubrina) (Vell.) Brenan, Jurema-branca $(P$. stipulacea) (Benth.) Ducke e Mulungu ( $E$. velutina Willd.), cujas sementes foram obtidas por meio de doações oriundas da Embrapa Semiárido, do Núcleo de Ecologia e Monitoramento Ambiental (NEMA) e mesmo por coletas realizadas em indivíduos presentes no em torno da área experimental. As sementes foram submetidas aos seguintes tratamentos pré-germinativos: T1testemunha sem aplicação de tratamento para quebra de dormência, T2-escarificação mecânica em extremidade oposta ao hilo com lixa de madeira, T3-escarificação mecânica em extremidade oposta ao hilo com lixa de madeira + imersão em água a temperatura ambiente por 24 horas e T4-tratamento térmico com imersão em água a $80^{\circ} \mathrm{C}$, por 2 minutos.

Depois de submetidas aos tratamentos pré-germinativos, as sementes foram semeadas em bandejas constituídas de polipropileno, contendo solo previamente peneirado em malha de dois $\mathrm{mm}$, coberto com vermiculita e umedecido diariamente. As bandejas foram alocadas em um viveiro, coberto com sombrite $70 \%$. Foi adotado o delineamento experimental inteiramente casualizado, com quatro repetições e 15 unidades cada, totalizando 60 sementes por tratamento. Cerca de 20 dias após a germinação, as mudas foram transplantadas para recipientes maiores de polipropileno de $300 \mathrm{~mL}$, contendo o mesmo substrato utilizado nas bandejas devido à limitação de espaço que interfere no desenvolvimento radicular da planta.

Para a avaliação da eficiência dos tratamentos pré-germinativos, foram analisados os seguintes parâmetros: Primeira contagem de germinação e Emergência de plântulas: As contagens do número de sementes germinadas iniciaram-se no dia seguinte à semeadura $\mathrm{e}$ estenderam-se até 30 dias após a emergência, definido, segundo Brasil (2009), pelo número de sementes que emergiram plântulas normais com cotilédones acima da superfície do solo. O Índice de velocidade de emergência (IVE) foi calculado utilizando-se a Equação 1, proposta por Maguire (1962):

$$
\mathrm{IVE}=\frac{\mathrm{E} 1}{\mathrm{~N} 1}+\frac{\mathrm{E} 2}{\mathrm{~N} 2}+\Lambda \frac{\mathrm{En}}{\mathrm{Nn}}
$$

onde $\mathrm{E} 1, \mathrm{E} 2, \ldots \mathrm{En}=$ número de plântulas normais anotadas na primeira contagem, na segunda contagem e na última contagem; $\mathrm{N} 1, \mathrm{~N} 2, \ldots \mathrm{Nn}=$ número de dias da semeadura até a primeira, segunda e última contagem.

Adicionalmente, aos 20 dias após a germinação, foram realizadas análises biométricas para uma melhor compreensão da influência dos tratamentos pré-germinativos no desenvolvimento das mudas, nas quais foram analisados: altura das plântulas $(\mathrm{cm})$, diâmetro do coleto $(\mathrm{cm})$ com auxílio de um paquímetro, sendo consideradas informações obtidas a $1,0 \mathrm{~cm}$ de altura da superfície do solo e número de folhas verdes completamente desenvolvidas. Os dados foram analisados por meio do cálculo de médias e desvio padrão. Adicionalmente, foi realizada a análise de variância (ANOVA) e o teste de Tukey ao nível de significância de 5\% com uso do software ASSISTAT v.7.7 (Silva \& Azevedo, 2016).

\section{Resultados}

Em ambos os experimentos se constatou que o tratamento da testemunha (T1) implicou em menores taxas da porcentagem de germinação, quando comparado aos demais tratamentos para todas as espécies. Para o Angico (A. colubrina), Jurema-branca $(P$. stipulacea) e Mulungu (E. velutina), a aplicação deste tratamento implicou em uma redução, quando comparados ao tratamento que apresentou maior percentual de germinação da ordem de $15 \%, 88 \%$ e $94 \%$, e $15 \%, 35 \%$ e $62 \%$, respectivamente, para a primeira e segunda épocas de semeadura (Figura 3ab). Apesar disso, na segunda época (Figura 3b), a porcentagem de emergência das sementes de $E$. 
velutina do T1 foi maior do que o observado nas sementes que foram submetidas ao tratamento $\mathrm{T} 4$
(Imersão em água a $80^{\circ} \mathrm{C}$ por 2 minutos).

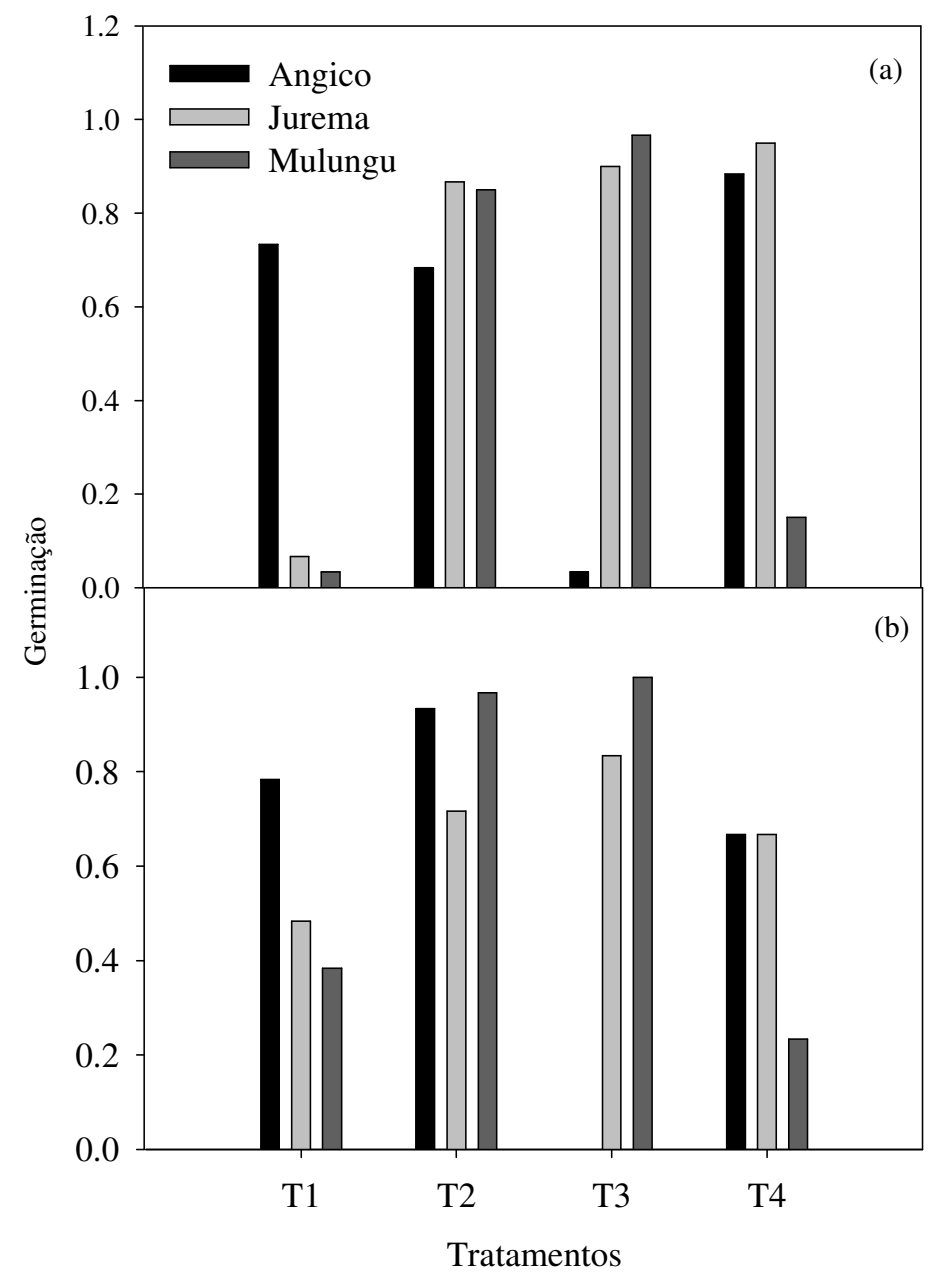

Figura 3. Porcentagens de germinação das espécies angico (Anadenanthera colubrina) (Vell.) Brenan, jurema-branca (Piptadenia stipulacea) (Benth.) Ducke e mulungu (Erythrina velutina Willd), em decorrência da aplicação dos tratamentos pré-germinativos: T1 = Testemunha, T2 = Escarificação mecânica oposta ao hilo com lixa de madeira, T3 = Escarificação mecânica oposta ao hilo com lixa de madeira + imersão em água por 24 horas, $\mathrm{T} 4=$ Imersão em água a $80^{\circ} \mathrm{C}$ por 2 minutos, durante a primeira (a) e segunda (b) épocas de realização do experimento, Serra Talhada-PE.

Para A. colubrina, em ambas as fases, pode-se constatar que os tratamentos T1, T2 e T4 apresentaram bons desempenhos $\mathrm{e}$ foram influenciadas pelas variações ambientais, com percentuais de germinação superiores à $80 \%$, para ambas as épocas. O tratamento T3 (Escarificação mecânica oposta ao hilo com lixa de madeira + imersão em água por 24 horas) por outro lado, mostrou-se ineficiente logo que ocasionou a embebição excessiva do tegumento que culminou com seu apodrecimento. Para $P$. stipulacea, os tratamentos T2, T3 e T4 não apresentaram diferenças significativas $(\mathrm{p}>0,05)$ quanto aos percentuais de germinação, todavia, quando se estabeleceu uma comparação entre os dados obtidos nas diferentes épocas, percebeu-se que a segunda promoveu uma redução destes em torno de $20 \%$.
Em relação à espécie E. velutina, em ambas as fases, o tratamento T3 (Escarificação mecânica oposta ao hilo com lixa de madeira + imersão em água por 24 horas), foi o que possibilitou maior porcentual de emergência de plântulas com valores de $97 \%$ na fase I e 100\% na fase II.

Para as demais variáveis: índices de velocidade de emergência (IVE), altura das plântulas, número de folhas e diâmetro do coleto observou-se que houve efeito significativo $(\mathrm{p}<$ $0,05)$ para interação tripla (época/espécie/tratamento pré-germinativo). Para o IVE da jurema-branca ( $P$. stipulacea) e do mulungu (E. velutina) os melhores resultados foram obtidos quando se aplicou o tratamento T3 (Escarificação mecânica oposta ao hilo com lixa de madeira + imersão em água por 24 horas), em 
ambas as épocas. Neste caso, embora a espécie Mulungu tenha apresentado maiores magnitudes das médias, as quais alcançaram valores de até 14,82 , estes não foram estatisticamente diferentes daqueles obtidos para a aplicação do mesmo tratamento com a jurema. Para o angico (A. colubrina), o tratamento $\mathrm{T} 2$, com escarificação mecânica oposta ao hilo, utilizando lixa de madeira, foi responsável pelos maiores IVE, tanto na fase I $(7,54)$, quanto na fase II $(4,24)$, sendo que na primeira época, o T2 não diferiu estatisticamente do T1 ( $p>0,05)$ (Tabela 2).

Tabela 2. Índices de Velocidade de Emergência (IVE) de plântulas de angico (Anadenanthera colubrina) (Vell.) Brenan, jurema-branca (Piptadenia stipulacea) (Benth.) Ducke e mulungu (Erythrina velutina Willd.) de sementes submetidas aos tratamentos pré-germinativos: T1 = Testemunha, T2 $=$ Escarificação mecânica oposta ao hilo com lixa de madeira, T3 = Escarificação mecânica oposta ao hilo com lixa de madeira + imersão em água por 24 horas, T4 = Imersão em água a $80^{\circ} \mathrm{C}$, por 2 minutos, durante a primeira (a) e segunda (b) épocas de realização do experimento, Serra Talhada-PE.

\begin{tabular}{cccccc}
\hline \multirow{2}{*}{ Épocas } & \multirow{2}{*}{ Espécies } & $\cdots$ & \multicolumn{4}{c}{ Tratamentos } & T2 & T3 & T4 \\
\hline \multirow{2}{*}{1} & Jurema & $0,11 \mathrm{D}$ & $2,22 \mathrm{~B}$ & $4,2 \mathrm{~A}$ & $1,12 \mathrm{C}$ \\
& Angico & $7,49 \mathrm{~A}$ & $7,54 \mathrm{~A}$ & $0,38 \mathrm{C}$ & $5,11 \mathrm{~B}$ \\
& Mulungu & $0,04 \mathrm{C}$ & $1,74 \mathrm{~B}$ & $7,98 \mathrm{~A}$ & $0,24 \mathrm{C}$ \\
\multirow{2}{*}{2} & Jurema & $0,97 \mathrm{~B}$ & $1,20 \mathrm{~B}$ & $3,08 \mathrm{~A}$ & $1,23 \mathrm{~B}$ \\
& Angico & $3,32 \mathrm{~B}$ & $4,24 \mathrm{~A}$ & $0,00 \mathrm{C}$ & $3,28 \mathrm{~B}$ \\
& Mulungu & $0,44 \mathrm{C}$ & $2,46 \mathrm{~B}$ & $14,82 \mathrm{~A}$ & $0,31 \mathrm{C}$ \\
\hline
\end{tabular}

Médias seguidas de mesma letra maiúscula na linha, não diferem estatisticamente entre si, pelo teste de Tukey ao nível de 5\% de probabilidade.

A análise das plântulas formadas a partir da aplicação dos diferentes tratamentos prégerminativos, permitiu constatar que as maiores magnitudes de valores da altura foram observadas na primeira época, entretanto, estes não foram significativamente diferentes da segunda. Quando se estabeleceu a comparação dos valores para uma mesma espécie, pode-se constatar que os tratamentos T2, T3 e $\mathrm{T} 4$ para a jurema apresentaram semelhança quanto à altura. Para o angico foram observadas as maiores médias para o T1 e T2, todavia, não se constataram diferenças entre estes e o T4 ( $>00,05)$, na mesma época e entre épocas (Tabela 3). O mulungu apresentou variações no comprimento da parte aérea em decorrência da época e tratamentos aplicados.

Tabela 3. Altura de plântulas, número de folhas vivas e diâmetro do caule das espécies angico Anadenanthera colubrina (Vell.) Brenan), jurema-branca (Piptadenia stipulacea) e mulungu (Erythrina velutina), oriundas de sementes submetidas aos seguintes tratamentos pré-germinativos para quebra da dormência na fase I: T1 = Testemunha, T2 = Escarificação mecânica oposta ao hilo com lixa de madeira, T3 = Escarificação mecânica oposta ao hilo com lixa de madeira + imersão em água por 24 horas, T4 = Imersão em água a $80^{\circ} \mathrm{C}$ por 2 minutos, no município de Serra Talhada-PE.

\begin{tabular}{|c|c|c|c|c|c|}
\hline \multirow{3}{*}{ Épocas } & \multirow{3}{*}{ Espécies } & \multicolumn{4}{|c|}{ Altura das plantas (cm) } \\
\hline & & \multicolumn{4}{|c|}{ Tratamentos } \\
\hline & & T1 & T2 & T3 & T4 \\
\hline \multirow{3}{*}{1} & Jurema & $0,00 \mathrm{~B}$ & $7,54 \mathrm{~A}$ & $6,96 \mathrm{~A}$ & $8,09 \mathrm{~A}$ \\
\hline & Angico & $5,69 \mathrm{~A}$ & $5,10 \mathrm{~A}$ & $0,00 \mathrm{~B}$ & $4,65 \mathrm{~A}$ \\
\hline & Mulungu & $5,50 \mathrm{C}$ & $9,38 \mathrm{~B}$ & $11,71 \mathrm{~A}$ & $10,00 \mathrm{AB}$ \\
\hline \multirow{3}{*}{2} & Jurema & $2,24 \mathrm{~A}$ & $2,03 \mathrm{~A}$ & $2,59 \mathrm{~A}$ & $1,69 \mathrm{~A}$ \\
\hline & Angico & $2,43 \mathrm{~A}$ & $2,99 \mathrm{~A}$ & $0,00 \mathrm{~B}$ & $2,73 \mathrm{~A}$ \\
\hline & Mulungu & $6,83 \mathrm{AB}$ & $8,34 \mathrm{~A}$ & $6,58 \mathrm{~B}$ & $6,49 \mathrm{AB}$ \\
\hline & & \multicolumn{4}{|c|}{ Número de folhas (unidades) } \\
\hline \multirow{4}{*}{1} & Jurema & $0,00 \mathrm{~B}$ & $6,88 \mathrm{~A}$ & $7,38 \mathrm{~A}$ & $7,50 \mathrm{~A}$ \\
\hline & Angico & $19,75 \mathrm{~A}$ & $17,25 \mathrm{~A}$ & $0,00 \mathrm{~B}$ & $14,75 \mathrm{~A}$ \\
\hline & Mulungu & $4,00 \mathrm{~A}$ & $5,37 \mathrm{~A}$ & $5,63 \mathrm{~A}$ & $4,25 \mathrm{~A}$ \\
\hline & Jurema & $5,69 \mathrm{~A}$ & $5,86 \mathrm{~A}$ & $5,38 \mathrm{~A}$ & $4,84 \mathrm{~A}$ \\
\hline \multirow[t]{3}{*}{2} & Angico & $9,25 \mathrm{~A}$ & $10,25 \mathrm{~A}$ & $0,00 \mathrm{~B}$ & $11,12 \mathrm{~A}$ \\
\hline & Mulungu & $2,00 \mathrm{~A}$ & $2,00 \mathrm{~A}$ & $2,00 \mathrm{~A}$ & $2,00 \mathrm{~A}$ \\
\hline & & \multicolumn{4}{|c|}{ Diâmetro do coleto (cm) } \\
\hline 1 & Jurema & $0,00 \mathrm{~B}$ & $0,10 \mathrm{~A}$ & $0,10 \mathrm{~A}$ & $0,10 \mathrm{~A}$ \\
\hline
\end{tabular}




$\begin{array}{cccccc} & \text { Angico } & 0,11 \mathrm{~A} & 0,10 \mathrm{~A} & 0,00 \mathrm{~B} & 0,10 \mathrm{~A} \\ & \text { Mulungu } & 0,30 \mathrm{C} & 0,46 \mathrm{~B} & 0,56 \mathrm{~A} & 0,48 \mathrm{~B} \\ & \text { Jurema } & 0,08 \mathrm{~A} & 0,08 \mathrm{~A} & 0,09 \mathrm{~A} & 0,08 \mathrm{~A} \\ & \text { Angico } & 0,09 \mathrm{~A} & 0,09 \mathrm{~A} & 0,00 \mathrm{~B} & 0,09 \mathrm{~A} \\ & \text { Mulungu } & 0,38 \mathrm{~A} & 0,41 \mathrm{~A} & 0,38 \mathrm{~A} & 0,39 \mathrm{~A}\end{array}$

Médias seguidas de mesma letra maiúscula na linha, não diferem estatisticamente entre si, pelo teste de Tukey ao nível de 5\% de probabilidade.

No caso do diâmetro, não foram observadas diferenças nos valores das espécies jurema e angico $(p>0,05)$, exceto nos tratamentos que comprometeram a germinação, neste caso, T1 e $\mathrm{T} 3$, respectivamente. O mulungu apresentou maior diâmetro quando comparado as demais espécies, que oscilou entre 0,3 e $0,56 \mathrm{~cm}$ (Tabela $3)$. No caso do número de folhas, observou-se que embora não tenham sido constatadas diferenças ( $\mathrm{p}$ $>0,05)$ entre épocas e tratamentos, na primeira época a emissão de folhas foi favorecida com destaque para o T2 e T3 para mulungu e jurema e T1 e T4 para o angico (Tabela 3).

\section{Discussão}

Baixos percentuais de germinação em sementes de $P$. stipulacea e E. velutina., em decorrência da ausência da aplicação tratamentos (T1) para quebra da dormência foram constatados por Farias et al. (2013) e Silva et al. (2007). Evidenciando a dormência nas sementes destas espécies. Por outro lado, o fato da porcentagem de emergência das sementes de E. velutina do T1 ter sido maior que as sementes submetidas ao tratamento $\mathrm{T} 4$ (imersão em água a $80^{\circ} \mathrm{C}$ por 2 minutos) durante a segunda fase pode ser atribuído ao fato deste último tratamento apresentar baixa eficiência quando comparado a outros (Tedesco, 2001). Devido às modificações fisiológicas nas sementes submetidas a temperaturas de $80^{\circ} \mathrm{C}$, que podem ter comprometido a germinação que, segundo Marcos Filho (2005), é um processo complexo e envolve uma série de mecanismos específicos, especialmente enzimáticos. Silva et al. (2014) citam que a temperatura ótima para a germinação de sementes de espécies tropicais oscila entre $25^{\circ} \mathrm{C}$ e $30^{\circ} \mathrm{C}$, e temperaturas mais baixas podem culminar com a redução do metabolismo e um aumento no tempo necessário para a germinação. Segundo Pereira (2011), as sementes de mulungu necessitam de tratamentos pré-germinativos e possuem um porcentual de emergência de $88 \%$. Santos et al. (2013), ao estudarem diferentes métodos para superação de dormência em sementes de E. velutina, encontraram valores inferiores e similares, quando usaram os tratamentos de escarificação na extremidade oposta à micrópila (98\%) e escarificação junto à micrópila (93\%).

As sementes de $A$. colubrina não mostraram sensibilidade aos tratamentos, indicando que as mesmas podem apresentar germinação rápida associada a altas taxas germinativas mesmo em condições naturais (Pereira, 2011). O apodrecimento das sementes de A. colubrina, quando submetidas ao tratamento $\mathrm{T} 3$, pode ter sido ocasionado devido a danos no processo germinativo. A embebição das sementes pode, em alguns casos, promover modificações ao nível de membranas, com consequente perda dos conteúdos celulares (Castro et al., 2004). Além disso, o excesso de umidade pode favorecer o desenvolvimento de doenças fúngicas $\mathrm{e}$ comprometer o vigor das sementes. Essas respostas, no entanto, podem variar em decorrência da espécie analisada e dos fatores ambientais.

Os maiores valores de IVE para o mulungu, na segunda época, foram, provavelmente, favorecidos pelas menores temperaturas e que culminaram com uma maior rapidez na emergência das plântulas, visto em torno de $25^{\circ} \mathrm{C}$, considerada dentro da faixa ótima, segundo Demuner et al. (2008). Guimarães et al. (2011) encontraram valores de IVE para o mulungu que oscilaram entre 5,13 e 6,17. Os altos índices de velocidade de emergência sugerem que as sementes germinam rapidamente sob condições ambientais favoráveis, evidenciando seu vigor (Oliveira et al., 2012).

Farias et al. (2013), analisando a superação de dormência na jurema-branca, constataram valores de altura que oscilaram entre 5,8 e $7,1 \mathrm{~cm}$, semelhantes aos obtidos neste estudo. Os maiores diâmetros do coleto determinados para o mulungu, em relação aos demais, podem ser justificados pelas características intrínsecas desta espécie, que apresenta maior crescimento, investindo menos em formação de madeira. Nesta condição, observou-se uma grande variação da espessura do coleto entre os tratamentos na primeira época, quando se perceberam maiores médias para o T3. Para Souza et al. (2006), a variação do diâmetro do caule, observada em mudas de uma mesma espécie após a germinação, é extremamente 
importante, visto que está associada à taxa de sobrevivência dos indivíduos. Ainda de acordo com estes autores, plantas que apresentam maior diâmetro do coleto, proporcionam maior capacidade de formação de raízes e, assim, maior possibilidade de sobrevivência.

Este comportamento pode ter sido favorecido pelas condições meteorológicas observadas neste período e que podem ter culminado com a maior formação de biomassa foliar, com reflexos no crescimento das plantas. $\mathrm{O}$ número de folhas apresenta uma relação intrínseca com a produção primária das plantas, visto que representa a principal estrutura para a realização da fotossíntese, além de acumular substâncias (como auxinas) que contribuem com a formação de novas estruturas vegetais (Araújo \& Sobrinho, 2011).

\section{Conclusão}

Sementes de Jurema-branca $(P$. stipulacea) e Mulungu (E. velutina) submetidas aos tratamentos pré-germinativos T2 e T3 apresentam melhores desempenhos germinativos que se refletem no crescimento da plântula. $\mathrm{O}$ Angico (A. colubrina) não foi sensível à aplicação dos tratamentos e a germinação foi anulada em decorrência da aplicação do tratamento T3.

As condições atmosféricas influenciam fortemente o comportamento da germinação e desenvolvimento de plântulas destas espécies sob condições de semiárido.

\section{Agradecimentos}

Ao Conselho Nacional de Desenvolvimento Científico e Tecnológico-CNPq e à Universidade Federal Rural de Pernambuco (UFRPE) pela concessão das bolsas do Programa de Iniciação Científica Voluntária (PIC) e infraestrutura disponibilizada para a realização deste estudo.

\section{Referências}

ALVARES, C. A.; STAPE, J. L.; SENTELHAS, P. C.; GONÇALVES, J. L. M.; SPAROVEK, G. 2013. Köppen's climate classification map for Brazil. Meteorologische Zeitschrift, v. 22, n. 6, p. 711-728.

ALVES, E. U.; ANDRADE, L. A.; BRUNO, R. L. A.; VIEIRA, R. M.; CARDOSO, E. A. 2011. Emergência e crescimento inicial de plântulas de Peltophorum dubium (Spreng.) Taubert sob diferentes substratos. Revista Ciência Agronômica, v. 42, n. 2, p. 439-447.
ANDRÉO-SOUZA, Y.; PEREIRA, A. L.; SILVA, F. F. S.; RIBEIRO-REIS, R. C.; EVANGELISTA, M. R. V.; CASTRO, R. D.; DANTAS, B. F. 2010. Efeito da salinidade na germinação de sementes e no crescimento inicial de mudas de pinhão-manso. Revista Brasileira de Sementes, v. 32, n. 2, p. 83-92.

ARAUJO, A. P.; PAIVA SOBRINHO, S. 2011. Germinação e produção de mudas de tamboril (Enterolobium contortisiliquum (Vell.) Morong) em diferentes substratos. Revista Árvore, v. 35, n. 3, supl. 1, p. 581-588.

AZEREDO, G. A.; PAULA, R. C.; VALERI, S. V.; MORO, F. V. 2010. Superação de dormência de sementes de Piptadenia moniliformis Benth. Revista Brasileira de Sementes, v. 32, n. 2, p. 4958.

BARRETO, A. F.; BARBOSA, J. K. A. 2001. Mecanismos de resistência à seca que possibilitam a produção em condições do semi-árido nordestino. Anais $3^{\circ}$ Simpósio brasileiro de captação de água de chuva no Semiárido, Areia, PB, Brasil, ABCMAC. 9p.

BEZERRA, D. A. C. 2008. Estudo fitoquímico, bromatológico e microbiológico de Mimosa tenuiflora (Wild) Poiret e Piptadenia stipulacea (Benth) Ducke. Dissertação de Mestrado, Universidade Federal de Campina Grande, Paraíba. 63p.

BRASIL. 2009. Ministério da Agricultura, Pecuária e Abastecimento. In: Regras para análise de sementes. Brasília: SNAD/DNDV/CLAV, 398p.

CASTRO, R. D.; BRADFORD, K. J.; HILHOSRT, H. W. M. 2004. Embebição e reativação do metabolismo. In: FERREIRA, A. G.; BORGHETI, F. Germinação: do básico ao aplicado. Porto Alegre: Artmed, pp. 149-162.

DEMUNER, V. G.; ADAMI, C.; MAURI, J.; DALCOMO, S.; HEBLING, A. A. 2008. Influência da luz e da temperatura na germinação de sementes de Erythrina verna (Leguminosae, Papilionoideae). Museu de Biologia Professor Mello Leitão, v. 24, p. 101-110.

EMBRAPA-Empresa Brasileira de Pesquisa Agropecuária. 2013. Sistema brasileiro de classificação de solos. $3^{\mathrm{a}}$ edição. 
FARIAS, R. M.; FREITAS, R. M. O.; NOGUEIRA, N. W.; DOMBROSKI, J. L. D. 2013. Superação de dormência em sementes de jurema-branca (Piptadenia stipulacea). Revista de Ciências Agrárias, v. 56, n. 2, p. 160-165.

GUEDES, R. S.; ALVES, E. U.; SANTOSMOURA, S. S.; COSTA, E. G.; MELO, P. A. F. R. 2013. Tratamentos para superar dormência de sementes de Cassia fistula L. Revista Biotemas, v. 26, n. 4, p. 11-22.

GUIMARÃES, I. P.; COELHO, M. F. B.; BENEDITO, C. P.; MAIA, S. S. S.; NOGUEIRA, C. S. R.; BATISTA, P. F. 2011. Efeito de diferentes substratos na emergência e vigor de plântulas de mulungú. Bioscience Journal, v. 27, n. 6 , p. 932-938.

INSTITUTO NACIONAL DO SEMIÁRIDO. Sinopse do Censo Demográfico para o Semiárido Brasileiro. Disponível em: http://www.insa.gov.br/wpcontent/themes/insa_theme/acervo/sinopse.pdf. Acesso em: 14 de abril de 2017.

LORENZI, H. 2008. Árvores Brasileiras: Manual de identificação e cultivo de plantas arbóreas nativas do Brasil.

LORENZI, H. 2009. Árvores Brasileiras: Manual de identificação e cultivo de plantas arbóreas nativas do Brasil. (Ed.) Nova Odessa, São Paulo.

MAGUIRE, J. D. 1962. Speed of germination aid in selection and evaluation for seedling emergence and vigor. Magazine Crop Science, v. 2, n. 1, p. 176-177.

MARENGO, J. A.; ALVES, L. M.; BESERRA, E. A.; LACERDA, F. F. 2011. Variabilidade e mudanças climáticas no semiárido brasileiro. Campina Grande-PB. (Ed.) Instituto Nacional do Semiárido.

OLIVEIRA, K. S.; OLIVEIRA, K. S.; ALOUFA, M. A. I. 2012. Influência de substratos na germinação de sementes de Anadenanthera colubrina (Vell.) Brenan em condições de casa de vegetação. Revista Árvore, v. 36, n. 6, p. 10731078.

PACHECO, M. V.; MATOS, V. P.; BARBOSA, M. D.; FERREIRA, R. L. C.; PASSOS, M. A. A. 2007. Germinação de sementes de Platypodium elegans Vog. submetidas a diferentes tratamentos pré-germinativos e substratos. Revista Brasileira de Engenharia Agrícola e Ambiental, v. 11, n. 5, p. 497-501.

PECHE, P. M.; BARBOSA, C. M. A.; PIO, R.; SOUSA, P. H. A.; VALLE, M. H. 2016. Estratificação das sementes, ácido giberélico e temperatura na obtenção de porta-enxertos de caquizeiros. Revista Ciência Agronômica, v. 47, n. 2, p. 387-392.

PELAZZA, B. B.; SEGATO, S. V.; ROMANATO, F. N. 2011. Quebra de dormência em semente de Adenanthera pavonina L. Revista Nucleus, v. 8, n. 1, p. 305-314.

PEREIRA, I. S. 2013. Croton linearifolius: Produção de mudas e respostas fisiológicas ao estresse hídrico. Dissertação de Mestrado, Universidade Estadual do Sudoeste da Bahia, Itapetinga, Bahia. 56p.

PEREIRA, M. S. 2011. Manual técnico conhecendo e produzindo mudas da Caatinga. Fortaleza: Associação Caatinga. 60p.

PEREIRA, P. C.; SILVA, T. G. F.; ZOLNIER, S.; MORAIS, J. E. F.; SANTOS, D. C. 2015. Morfogênese da Palma forrageira irrigada por gotejamento. Revista Caatinga, v. 28, n. 3, p. 184195.

SANTOS, L. W.; COELHO, M. F. B.; MAIA, S. S. S.; SILVA, R. C. P.; CANDIDO, W. S.; SILVA, A. P. 2013. Armazenamento e métodos para a superação da dormência de sementes de mulungu. Semina: Ciências Agrárias, v. 34, n. 1, p. 171-178.

SILVA, F. A. S.; AZEVEDO, C. A. V. 2016. The Assistat Software Version 7.7 and its use in the analysis of experimental data. African Journal of Agricultural Research, v. 11, n. 39, p. 3733-3740.

SILVA, K. B.; ALVES, E. U.; BRUNO, R. L. A.; GONÇALVES, E. P.; BRAZ, M. S. S.; VIANA, J. S. 2007. Quebra de Dormência em Sementes de Erythryna velutina Willd. Revista Brasileira de Biociências, v. 5, supl. 2, p. 180-182.

SILVA, K. B.; ALVES, E. U.; OLIVEIRA, A. N. P.; SOUSA, N. A.; AGUIAR, V. A. 2014. Influência da luz e temperatura na germinação de sementes de quixaba. Revista Agropecuária Técnica, v. 35, n. 1, p. 13-22.

SOUZA, C. A. M.; OLIVEIRA, R. B.; MARTINS FILHO, S.; LIMA, J. S. S. 2006. Crescimento em 
Journal of Environmental Analysis and Progress V. 02 N. 04 (2017) 499-508

campo de espécies florestais em diferentes condições de adubação. Ciência Florestal, v. 16, n. 3, p. 243-249.

TEDESCO, S. B.; STEFANELLO, M. O.; SCHIFINO-WITTMANN, M. T.; BATTISTIN,
A.; DALL'AGNOL, M. 2001. Superação de dormência em sementes de espécies de Adesmia DC. (Leguminosae). Revista Brasileira de Agrociência, v. 7 n. 2, p. 89-92. 